\title{
Os liviros entre as cores e a conscientização de professores para o uso da biblioteca escolar
}

\author{
The books between colors and the awareness of teachers to use the school library
}

\begin{abstract}
Lucas Veras de Andrade
Especialista em Supervisão Educacional. Pedagogo com habilitação em Gestão Educacional. Bacharel em Biblioteconomia. Professor da Educação Básica da Secretaria Municipal de Educação de Teresina - PI. E-mail: lukkandrade18@hotmail.com
\end{abstract}

Ana Caroline Viana Costa Licenciatura em Pedagogia pela Universidade Federal do Piauí - UFPI e Especialização em Supervisão Educacional pela Universidade Estadual do Piauí - UESPI. E-mail: anacvcosta@ hotmail.com

Gisele Sousa Lobão Damasceno
Graduação em Licenciatura Plena em História - UFPI. Especialização em Supervisão Educacional e Professora da rede municipal de Teresina - PI. E-mail: giselledamasceno@ hotmail.com

Isaias Geovane Lima

Graduação em Licenciatura Plena em Educação Artística - UFPI. Especialização em Supervisão Educacional - UESPI e Professor da rede municipal de Piripiri - PI. E-mail: geovane.art@ hotmail.com

Iva de Carvalho da Silva Graduação em Licenciatura Plena em Educação Artística - UFPI. Especialização em Supervisão Educacional - UESPI e Professora da rede estadual do Piauí - SEDUC-PI. E-mail: ivabelha@ hotmail.com

Patrícia Viana Cardoso

Licenciatura em Normal Superior pelo Instituto Superior de Educação Antonino Freire. Especialização em Supervisão Educacional pela Universidade Estadual do Piauí - UESPI. Professora das Séries Iniciais do Ensino Fundamental da Secretaria Municipal de Educação de Teresina - PI. E-mail: patriciavcardoso@ hotmail.com

Licenciatura em Pedagogia pela Universidade Federal do Piauí - UFPI. Especialização em Supervisão Educacional pela Universidade Estadual do Piauí - UESPI. Professora da rede particular de Teresina - PI.

E-mail: chavesrere@ hotmail.com

Theodolina Beserra Torres

Licenciatura em Pedagogia pela Universidade Federal do Piauí - UFPI. Especialização em Supervisão Educacional pela Universidade Estadual do Piauí - UESPI. E-mail: lukkandrade22@ hotmail.com

Willian Lamartins Amorim da Silva

Licenciatura em Pedagogia pela Universidade Federal do Piauí - UFPI. Especialização em Supervisão Educacional pela Universidade Estadual do Piauí - UESPI. Professor das Séries Iniciais do Ensino Fundamental da Secretaria Municipal de Educação de Teresina - SEMEC. E-mail: $\underline{\text { wl_amorim@ hotmail.com }}$

\section{Resumo}

O presente trabalho tem por objetivo relatar as atividades desenvolvidas durante o Estágio Supervisionado do curso de Especialização em Supervisão Educacional da Universidade Estadual do Piauí (UESPI), para promover a utilização da biblioteca escolar de uma unidade educacional da rede estadual no município de Teresina (PI). Em um diagnóstico constatou-se que a biblioteca da escola não efetiva as suas finalidades e objetivos. A motivação para tal, segundo os discursos proferidos pela gestora e supervisora decorre da ausência de um profissional no espaço da biblioteca escolar. Nosso projeto interventivo foi desenvolvido com o intuito de desmitificar esta concepção a partir da conscientização dos docentes e de toda a equipe pedagógica da escola a partir de atividades que permitissem uma reflexão sobre a importância deste espaço e principalmente a partir da organização mediante a classificação em cores que possibilita a organização e usabilidade do acervo de forma prática, sem necessariamente ter uma pessoa para viabilizar o empréstimo das obras.

Palavras-chave: Classificação em Cores. Biblioteca Escolar. Atividades no contexto da biblioteca Escolar.

Bibl. Esc. em Rev., Ribeirão Preto, v. 2, n. 1, p. 69-88, 2013. 


\begin{abstract}
This study aims to report the activities undertaken during the Supervised Course of Specialization in Educational Supervision, State University of Piauí (UESPI), to promote the use of the school library an educational unit of the state in the city of Teresina (PI .) In a diagnosis it was found that the school library ineffective its purposes and objectives. The motivation for this, according to the speeches made by the manager and supervisor is the lack of a professional within the school library. Our interventionist project was developed in order to demystify this concept from the awareness of teachers and the entire teaching staff of the school based activities that enable a reflection on the importance of this area and especially from the organization by classification in color permits the organization and usability of the acquis in a practical way, without necessarily having a person to enable the loan works.
\end{abstract}

Keywords: Color Classification. School Library. Activities within the school library.

\title{
1. Introdução
}

São várias as ideias construídas no imaginário a respeito da biblioteca escolar. Ora é um lugar de imposição do silêncio, onde os alunos são impedidos de exporem no lócus sua subjetividade a respeito da obra lida com os colegas. Outra é um lugar de armazenamento, pesquisa e consulta, ou seja, uma ideia altamente burocratizada e por fim, em minoria um lugar de prazer, de encontro, de conhecimento e informação.

$\mathrm{Na}$ verdade, poucos (re) conhecem os reais objetivos e funções de uma biblioteca e principalmente da escolar. Nossa afirmação converge ao que Fragoso (2002, p. 142) afirma "o fato é que, quando se trata de Brasil, a maioria das pessoas desconhece o verdadeiro papel de uma biblioteca em suas vidas e, portanto, na vida da comunidade".

Embora tão mal compreendida, indiscutivelmente ela possui uma relevância ímpar no contexto escolar. Cabe a mesma a partir da sua mediação e ao estímulo do seu uso, o desenvolvimento de diversas competências no alunado, devendo também ser usada pelo professor para respaldar sua prática docente, cooperando assim, com o currículo educacional.

Partindo da compreensão acima mencionada, ou seja, da importância da biblioteca na escola é que o presente trabalho relatará atividades desenvolvidas a partir de um projeto interventivo oportunizado mediante o Estágio Supervisionado do curso de Especialização em Supervisão Educacional da Universidade Estadual do Piauí (UESPI) na biblioteca escolar da Unidade Desembargador Pedro Conde, sediada no município de Teresina (PI).

O projeto em questão teve como objetivo: organizar o acervo da biblioteca da escola mencionada a partir da classificação em cores e promover o seu uso mediante conscientização de professores da sua importância. A escolha do espaço da biblioteca para a intervenção se 
Lucas Veras de Andrade, Ana Caroline Viana Costa, Gisele Sousa Lobão Damasceno, Isaias Geovane Lima, 71 Iva de Carvalho da Silva, Patrícia Viana Cardoso, Renata Chaves de Oliveira, Theodolina Beserra Torres e Willian Lamartins Amorim da Silva

deu a partir de alguns critérios. Um foi a questão da autonomia que o grupo teve na execução das atividades propostas e outro foi de termos um profissional bibliotecário como componente do grupo respaldando as atividades com base em teóricos da área de Biblioteconomia.

O trabalho se torna relevante na medida em que permite uma reflexão sobre o espaço da biblioteca no ambiente escolar e propõe atividades lúdicas ao professorado. Outra contribuição incide diretamente na figura do bibliotecário e na necessidade da inserção deste no ambiente escolar. Em nossa intervenção, fica evidente pela complexidade das atividades a serem empreendidas neste espaço que vão desde a organização até o desenvolvimento racional da coleção que este por sua formação é o profissional mais habilitado a estar à frente e desenvolver toda a potencialidade deste espaço no contexto educacional.

Estruturamos nosso trabalho em seis seções. Inicialmente, temos a introdução onde evidenciamos os objetivos e as contribuições da nossa intervenção. A segunda temos uma breve discussão teórica onde apresentamos aspectos conceituais da biblioteca escolar. Logo após temos o diagnóstico situacional da biblioteca escolar da instituição supracitada, onde pautamos alguns aspectos que foram analisados como: acervo, características físicas e uso da biblioteca pelos alunos.

Em seguida temos a metodologia, o percurso percorrido. Nesta explanamos os instrumentos que subsidiaram a coleta de dados e nos permitiram pensar em um plano de ação interventivo. Na quinta seção, enfocamos as ações empreendidas e por fim tecemos algumas considerações com base em nossas observações.

\section{Biblioteca Escolar: aspectos conceituais}

A palavra biblioteca tem sua origem na palavra grega bibliotheke, resultado da junção de duas palavras, biblio e tëke, que significam respectivamente, livro e depósito. No entanto o conceito da palavra biblioteca vem se modificando com o tempo e acredita-se na mudança de que essa ideia já não mais pertença à comunidade escolar que se mostra inserido em um novo conceito mais participativo e amplo, conforme se apresenta na Lei $\mathrm{n}^{\circ} 12.244$, sancionada em 2010 que prevê a universalização das bibliotecas escolares no Brasil.(BRASIL, 2010).

Segundo Pimentel, Bernardes e Santana (2007, p. 23) a biblioteca escolar se constitui como "centro de recursos educativos, integrado ao processo de ensino-aprendizagem, tendo 
como objetivo primordial desenvolver e fomentar a leitura e a informação". Sendo a escola um espaço de aprendizagem permanente, que ela contribua para qualidade de ensino, para a formação da linguagem escrita e que o aluno possa desenvolver suas potencialidades ajudando, assim, no crescimento da escola.

Nesse sentido, a biblioteca escolar não deve ser só um espaço de ação pedagógica, servindo como apoio à construção do conhecimento e de suporte a pesquisas, esta deve ser um ambiente para que todos que usufruam possam utilizá-la como uma fonte de experiência, exercício da cidadania e formação para a vida.

\section{Diagnóstico Situacional da Biblioteca Escolar da Unidade Escolar Desembargador Pedro Conde}

Desenvolvemos o diagnóstico mediante duas etapas. $\mathrm{Na}$ primeira, fizemos $\mathrm{o}$ levantamento e avaliação dos recursos humanos existentes na biblioteca em questão e na segunda o inventário dos recursos informacionais como, por exemplo: material (mobiliário e equipamentos), localização da biblioteca e coleção (livros, periódicos e etc.).

Com relação à primeira etapa constatamos a existência de um profissional, sendo este professor afastado das atividades docentes e motivação para tal não revelada. $O$ perfil deste vai ao encontro com o que a literatura coloca a respeito dos profissionais que estão à frente deste espaço, sendo estes professores. Evidenciando ainda, estes ao final da carreira ou em função de patologias orgânicas.

Vários foram os aspectos analisados na segunda etapa. A biblioteca em questão tem como lócus uma sala própria dentro das acomodações da Unidade Escolar Pedro Conde. A infraestrutura da mesma conta com mobiliário novo, ventilação e iluminação apropriada para o desenvolvimento das atividades fins da biblioteca. Esclarecendo que pontuamos ventilação e iluminação como relativa, porque em nossas observações constatamos que ambas possuem toda a infraestrutura necessária para ser ideal, no entanto as mesmas não se apresentam assim.

A iluminação é um aspecto bem relevante dentro do contexto de uma biblioteca principalmente por dois aspectos. Um pelo conforto ao usuário e o outro pela conservação do acervo. Para este último é recomendado o uso de lâmpadas fluorescentes com protetores tipo 
Lucas Veras de Andrade, Ana Caroline Viana Costa, Gisele Sousa Lobão Damasceno, Isaias Geovane Lima, 73 Iva de Carvalho da Silva, Patrícia Viana Cardoso, Renata Chaves de Oliveira, Theodolina Beserra Torres e

Willian Lamartins Amorim da Silva

membrana de plástico fino e flexível, impedindo assim, que o calor dos reatores fique próximo dos livros/ materiais/ acervo.

Em nossas observações diante destes aspectos, os definimos como oscilantes, uma vez que o ar condicionado só estar em funcionamento na presença de um indivíduo na biblioteca sendo assim, constantemente ligado e desligado e as janelas pela comodidade que o ar condicionado favorece nunca ou quase nunca são abertas.

Um ambiente nestas condições favorece ao surgimento de fungos e bactérias no acervo. É recomendado, por exemplo, para materiais do tipo papel (quase que total do acervo em análise) pela literatura especializada em conservação que a temperatura seja mantida permanente entre $19^{\circ}$ e $23^{\circ} \mathrm{C}$, pois o acervo nesses moldes é bastante sensível a mudanças bruscas de temperatura. $\mathrm{O}$ ideal é que o ar condicionado fique em funcionamento plenamente nas temperaturas recomendadas e que na inviabilidade de se manter o mesmo em pleno funcionamento e controlado, que se mantenha o ambiente arejado naturalmente.

O acervo da biblioteca em questão compõe-se de uma variedade de fontes de informações onde destacamos: periódicos, obras de referências, livros de caráter científico, livros didáticos entre outros. No geral, estes se apresentam em bom estado de conservação e se evidenciam bastante atuais, possuindo entre 4 e 6 anos de publicação.

Outros aspectos relevantes no contexto de uma biblioteca escolar são pisos e paredes. Com relação a estes, no contexto em pauta observamos os seguintes detalhes: facilidade de limpeza, nível do piso, acústica, aparência, bem como umidade nas paredes. Destes aspectos nada de negativo foi evidenciado. Com relação área de armazenamento do acervo, esta se encontra qualificada para sua utilização.

O mobiliário se mostrou funcional e apropriado e está pautado na durabilidade e flexibilidade, um exemplo são as estantes, que embora tradicionais, são fabricadas com materiais resistentes e em caso de reorganização do espaço da biblioteca, as mesmas possuem grande facilidade de remoção no que diz respeito à locomoção e portabilidade.

Embora o lócus em questão tenha nos demonstrado mais aspectos positivos do que negativos estes últimos também se fizeram presentes. A maioria dos títulos estavam empoeirados e as estantes muito próximas uma das outras, fazendo com que os livros ficassem amontoados. As prateleiras foram evidenciadas repletas de livros, o que denota um perigo ao consulente, pois as mesmas lotadas correm o risco de virarem e causar acidentes. 
Percebemos uma grande problematização com relação à organização do acervo e no que diz respeito à localização das obras, pois não existiam sinalizações e nada de processamento técnico, ou seja, nada que facilitasse o acesso do usuário às obras. Um componente do acervo a ressaltar são os periódicos. No espaço analisado não vimos uma diferenciação destes com o restante do acervo, ficando os mesmos juntamente com os livros didáticos.

A escola segundo nossa análise possui periódicos de boa qualidade, inclusive alguns voltados para o ensino/aprendizagem de grande relevância para a formação de professores, que poderia contribuir e muito no fazer docente e na reflexão da prática destes.

Outro aspecto observado e o mais grave. Em conversa informal tanto com a supervisora pedagógica quanto com a gestora nos foi evidenciado que a biblioteca escolar da instituição que aqui discutimos não efetiva sua função. Segundo as mesmas este aspecto decorre da ausência constante do responsável ficando esta fechada, um verdadeiro crime na contemporaneidade, onde a informação e o conhecimento são peças fundamentais na sociedade em que vivemos, a chamada sociedade da informação.

\section{Delineamento Metodológico: o caminho percorrido...}

Ao termos acesso a instituição Unidade Escolar Pedro Conde, fomos recebidos inicialmente pela supervisora pedagógica, onde nos apresentamos e colocamos nossa necessidade de ter a escola como lócus de estágio. Em seguida fomos apresentados a Gestora e em conjunto discutimos os objetivos do mesmo, tendo à finalidade de levantar demandas da instituição e a partir destas escolhermos uma e planejarmos uma intervenção pedagógica.

Em conversa breve tanto com a supervisora quanto com a gestora foram levantadas as seguintes demandas: desinteresse dos alunos, indisciplina, violência escolar e má utilização da biblioteca no contexto escolar pelos alunos. Destas, escolhemos o último aspecto por várias vertentes. A primeira por entendermos que o espaço a ser trabalhado nos possibilitaria uma maior autonomia no desenvolvimento das atividades como já citado, uma vez que as outras demandas exigiriam um contato maior com as profissionais até aqui citadas, que logo em nossa apresentação inicial imediatamente expuseram essa impossibilidade. A segunda por acreditarmos que muitas das dificuldades elencadas fogem da capacidade de resolução apenas em um projeto interventivo, e caso ocorresse teríamos que sermos orientados por uma equipe 
Lucas Veras de Andrade, Ana Caroline Viana Costa, Gisele Sousa Lobão Damasceno, Isaias Geovane Lima, 75 Iva de Carvalho da Silva, Patrícia Viana Cardoso, Renata Chaves de Oliveira, Theodolina Beserra Torres e Willian Lamartins Amorim da Silva

multiprofissional pelos aspectos a serem trabalhados estarem além da área de formação dos componentes do grupo, além de contar com parceria com centros de referências como Centro de Referência de Assistência Social (CRAS) e Centro Especializado de Assistência Social (CREAS).

E por fim, por crermos que a biblioteca seja um potencializador cultural que pode inclusive, minimizar as outras demandas não atendidas por nossa ação, uma vez que o indivíduo informado é capaz de refletir criticamente sobre causas e consequências acerca de temáticas diversas, o que faz com que ele se sinta inibido a desenvolver ou praticar determinadas ações.

Uma vez escolhida a demanda, decidimos logo os instrumentos de coletas de dados. Assim, nos utilizamos da observação participante, diário de campo e entrevista semiestruturada. Estes nos possibilitaram um melhor entendimento das análises e dos resultados de forma qualitativa. Laville (1999) compreende a observação participante como algo que permite ao pesquisador ver longe, e considerar várias facetas dentro de um contexto.

O diário de campo foi outra forma que nos permitiu colher dados riquíssimos. Por meio dele registramos todos os momentos da ação, fatos, dificuldades e principalmente os conflitos no decorrer das atividades, ou seja, tudo aquilo que se fez presente durante a execução. Nesse sentido nos alicerçamos em Trivinõs (1987) que pondera sobre este método no sentido de considerar as anotações como as primeiras buscas espontâneas de significados. Entende-se por entrevista semiestruturada aquela que é orientada por um roteiro frente questionamentos. (LÜDKE, 1986).

Uma vez escolhidos os métodos de coleta de dados, fez-se uma análise mediante observação inicial, em que se pode fazer o comparativo entre os discursos até então proferidos pela supervisora e a gestora da escola, com a realidade observada e a partir desta relação pensar em ações efetivas para promover mudanças no contexto de análise.

Desse modo, logo após delineamos as atividades a serem desenvolvidas no espaço da biblioteca escolar. Assim, a partir de nossa percepção dividimos a ação pedagógica em cinco momentos sendo estes subdivididos em etapas. No primeiro os autores via correio eletrônico (email) assim como, pelo grupo criado pela rede social Facebook esteve inteirado trocando ideias sobre um breve cronograma de execução elaborado por um dos participantes. 
O segundo momento denominado de diagnóstico, coletamos informações por meio do projeto político pedagógico da escola, conversa informal com as gestoras, entrevista, assim como pela observação estruturada, onde analisamos os seguintes itens: Estrutura da escola, organização do espaço da biblioteca, observação do acervo, modo de classificação, mobiliário entre outros aspectos.

O terceiro teve o planejamento das atividades. Definimos o que cada componente do grupo ficaria responsável por desenvolver e com base no diagnóstico, elencamos as ações interventivas. Ainda neste, buscamos saber o que a escola poderia nos ofertar para o desenvolvimento do que foi proposto pelo grupo.

Logo após tivemos a execução, esta foi desenvolvida inicialmente nos turnos da manhã e tarde e foi finalizada no turno da noite. O momento citado foi dividido em duas etapas, um inicial que foi marcado pela organização e a classificação em cores do acervo. Neste foi criado um cronograma ou ficha de ponto, onde cada componente de acordo com sua disponibilidade teria um dia ou dias imbuídos da responsabilidade de atingir a meta estabelecida pelo grupo no desempenho das atividades atribuídas a cada componente. Um aspecto importante a se ressaltar neste momento foi à comunicação do grupo, onde os componentes que executavam atividades no turno da manhã ou tarde ou vice-versa deixavam por escrito encaminhamentos para ser desenvolvido pelo grupo do contra turno. Dessa forma o grupo ganhou tempo e teve um trabalho mais consistente e coerente.

E por fim tivemos a culminância, onde na sala de vídeo apresentamos a toda equipe da escola uma palestra sobre a importância da biblioteca escolar bem como suas finalidades no intuito de esclarecer o potencial deste espaço, e como este pode agregar valores aos educandos e complementar na prática pedagógica dos professores. Nesta ainda demonstramos a situação encontrada na biblioteca e a realidade atual, assim como o sentido das ações que foram empreendidas no espaço. Também escolhemos de forma aleatória alguns alunos para enfocarmos o treinamento do usuário, uma vez que foi evidenciada a preocupação por parte da gestão escolar a questão a organização da biblioteca. Outro aspecto a ser mencionado com relação à escolha dos alunos mencionados é o sentido de os mesmos se tornarem multiplicadores, ou seja, os mesmos assim como os funcionários que participarem da explanação a cada início de ano dariam a mesma explicação aos alunos novatos, comentando o funcionamento da biblioteca e organização para que se utilizem do acervo de forma organizada. 
Lucas Veras de Andrade, Ana Caroline Viana Costa, Gisele Sousa Lobão Damasceno, Isaias Geovane Lima, 77 Iva de Carvalho da Silva, Patrícia Viana Cardoso, Renata Chaves de Oliveira, Theodolina Beserra Torres e Willian Lamartins Amorim da Silva

\section{Ações Realizadas}

As ações pensadas e executadas tiveram como eixo norteador as cinco leis da biblioteconomia, elaboradas pelo indiano Ranganathan. Segundo Targino (2010) as mesmas foram elaboradas em 1928 e somente publicadas em 1931. Ainda para a autora as leis se tornam relevantes na medida em que seus preceitos se tornam atuais e quando os indivíduos conseguem visualizar nas mesmas o exercício da cidadania na medida em que oportuniza "a todos as informações compatíveis às suas demandas informacionais e, portanto, lhes favorecendo a chance de exercitar direitos e deveres". (TARGINO, 2010, p. 122). Dessa forma, temos as seguintes leis:

1. Os livros são para usar.

2. A cada leitor seu livro.

3. A cada livro seu leitor.

4. Poupe o tempo do leitor.

5. A biblioteca é um organismo em crescimento.

A seguir as leis serão esclarecidas mediante as ações pensadas e empreendidas no lócus em questão. Dessa forma, acreditamos melhorar a compreensão destas, na medida em que colocamos a teoria e apresentamos a atividade prática desenvolvida.

\section{Atividade 1 - Organização e Classificação do Acervo}

Como já demonstrado anteriormente na biblioteca em questão, não encontramos nada no sentido de sinalização organizacional bem como de classificação do acervo. Desse modo, decidimos por organizá-la por assunto e classificá-la segundo a classificação em cores pela sua praticidade. Nossa escolha por este tipo de classificação foi pautada principalmente por acreditarmos que as cores chamariam atenção da clientela da biblioteca pela sua ludicidade que na sua maioria são crianças, e para os alunos maiores pela sua simplicidade na sua usabilidade. Segundo Pinheiro (2009) a classificação em cores é uma metodologia diferenciada e muito pouco aplicada no Brasil. Na visão de Pinheiro e Sachetti (2004) é um sistema de sinalização que se apropria não só da linguagem visual, ou seja, a estética, mas principalmente da facilidade do seu uso que possibilita uma melhor interação entre o consulente (estudante) e a informação. 
Assim, os livros foram divididos em três grandes grupos, sendo eles: acervo geral, periódicos e livros didáticos. Sendo o primeiro classificado em cores sob dois enfoques: o primeiro, literatura que foi subdividido pelos gêneros literários e o segundo livros de pesquisa onde se estabeleceu diversas cores para cada assunto. Os periódicos assim como os livros didáticos não houve necessidade de sinalização colorida por dois aspectos: a primeira pela quantidade encontrada e a segunda pela fácil compreensão do material, sendo os primeiros organizados por título e os livros didáticos subdivididos em ensino fundamental e médio e por disciplinas.

Além das atividades da classificação em cores, atribuímos algumas normas para a etiquetagem da tarja na lombada das obras. Colou-se em cada exemplar uma tarja de 1,5 centímetro de largura e de 7centímetros de comprimento, a classificação do assunto foi feita mediante a catalogação na fonte, que nesse estudo entendemos como aquela que o assunto é expresso mediante a ficha catalográfica. Assim, a seguir evidenciaremos mediante quadro 1, a classificação em cores que elaboramos e a respectiva organização do acervo.

Quadro 1: Organização do Acervo e Classificação em Cores

\begin{tabular}{|c|c|c|}
\hline Grupo 1 & Grupo2 & Grupo 3 \\
\hline Acervo Geral & Periódicos & Livros Didáticos \\
\hline Enfoque & Títulos & Ensino Médio \\
\hline Literatura & Nova Escola & \multirow{2}{*}{ Língua Portuguesa } \\
\hline Gêneros Liter & Revista Plenitude & \\
\hline L. Infanto Juvenil & Revista Veja & \multirow{2}{*}{ Matemática } \\
\hline Conto & Revista Istoé & \\
\hline Poesia & TV Escola & \multirow{2}{*}{ História } \\
\hline Romance & Mundo Estranho & \\
\hline Ficção & Cálculo & \multirow{2}{*}{ Geografia } \\
\hline Crônica & Carta na Escola & \\
\hline Novela & Revista Presença & \multirow{2}{*}{ Física } \\
\hline História em Quadrinhos & Você S/A & \\
\hline Teatro & Medicina e Saúde & \multirow[b]{2}{*}{ Química } \\
\hline Fábula & $\begin{array}{c}\text { Aventuras na } \\
\text { História }\end{array}$ & \\
\hline
\end{tabular}


Lucas Veras de Andrade, Ana Caroline Viana Costa, Gisele Sousa Lobão Damasceno, Isaias Geovane Lima, 79 Iva de Carvalho da Silva, Patrícia Viana Cardoso, Renata Chaves de Oliveira, Theodolina Beserra Torres e Willian Lamartins Amorim da Silva

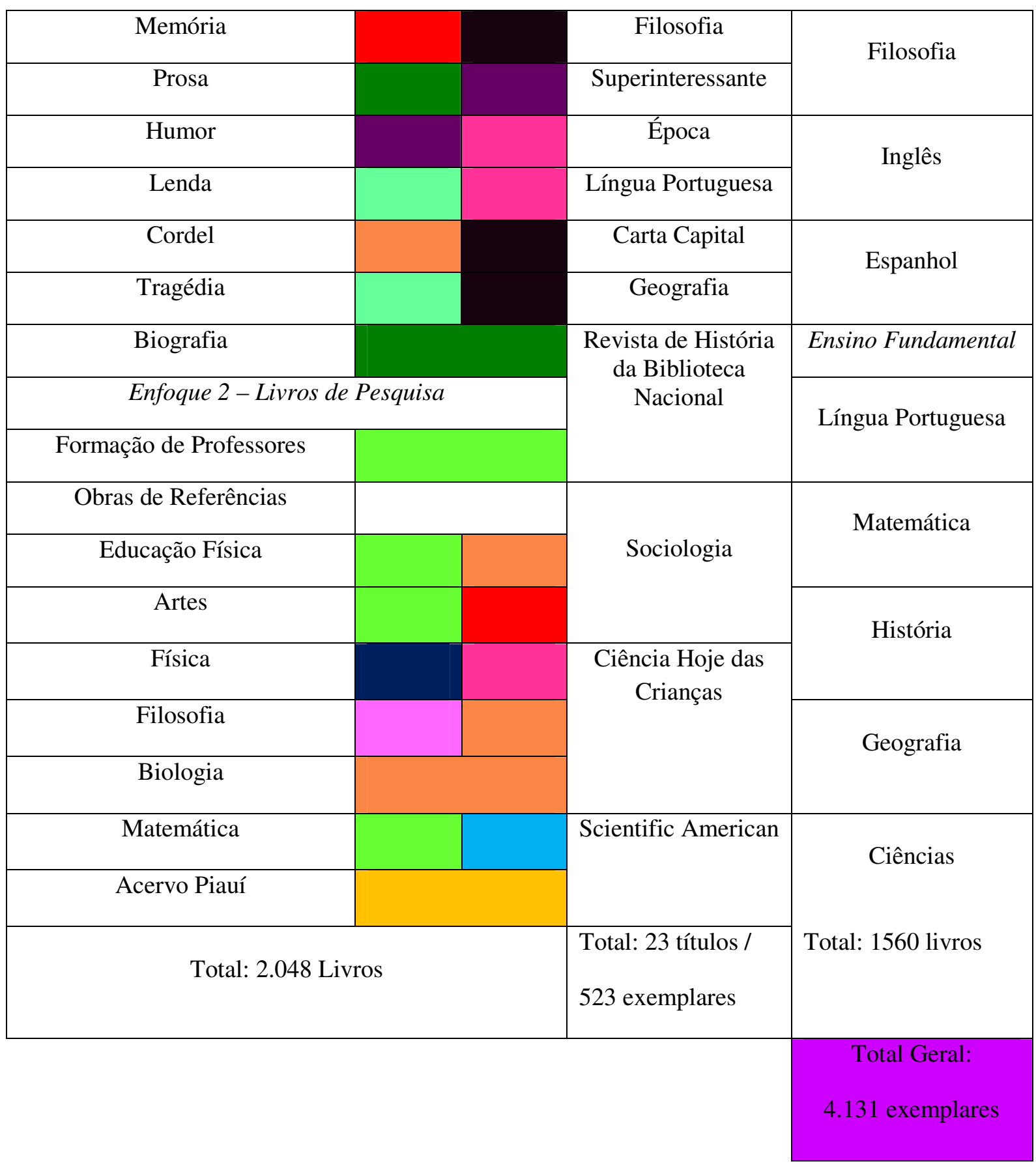

Fazendo a relação desta atividade com as leis de Ranganathan, podemos perceber claramente a ligação desta com a primeira e quarta lei. Na medida em que temos a intenção de darmos autonomia ao espaço da biblioteca com a classificação em cores e com a organização proposta como acima evidenciado, já que a organização foi uma das maiores preocupações evidenciadas pelas gestoras em nossas observações. Almejamos a usabilidade dos exemplares lá resguardados, uma vez que a classificação descrita permitirá que os alunos mesmo na ausência da pessoa responsável pelo espaço da biblioteca adentrem no espaço em pauta e escolham os livros a partir de suas demandas informacionais e ao devolverem os mesmos pela 
praticidade da classificação proposta manteriam o acervo organizado. Dessa forma, nossa vontade vai ao encontro do preceito da primeira lei, que os livros são para serem usados.

A quarta lei tem como lema poupe o tempo do leitor, na medida em que arrumamos o acervo por meio da organização e classificação em cores, nossa atitude serviu como uma ferramenta imprescindível para minimizar o tempo gasto pelo leitor na sua busca por informações e na procura dos livros, já que o mesmo ao se orientar pela legenda que define a cor e seu respectivo assunto e os locais dos outros tipos de materiais dará ao usuário mais condições e agilidade ao acesso às estantes e prateleiras. A seguir relataremos a atividade de número 2.

\section{Atividade 2 - Palestra aos professores sobre a importância da biblioteca escolar}

Por entendermos que na ausência de uma pessoa que esteja à frente da biblioteca com a incumbência de desenvolver suas atividades, cabe ao professor tentar na medida do possível, pois sabemos que durante o ano letivo várias são as demandas aos professores, minimizar a distância dos discentes a este espaço a partir do desenvolvimento de atividades que busquem aliar os conteúdos das disciplinas ao contexto de sala de aula. Desse modo, pensamos na conscientização dos professores e toda a equipe pedagógica da escola sobre a importância deste espaço no contexto educacional e sobre os benefícios que este traz para os alunos com relação ao desenvolvimento de competências nestes.

Assim, nesta atividade estavam presentes 18 professores, 2 coordenadores pedagógicos e a pessoa responsável pela biblioteca, totalizando vinte e uma pessoas. Inicialmente partimos da problematização: “O que pensamos sobre a biblioteca escolar?". Com este discutimos alguns aspectos como, por exemplo: a concepção dos professores acerca do espaço em pauta, a vivência destes frente este espaço na condição de acadêmicos e profissionais da educação e o estímulo que estes professores empreendem aos discentes da escola no sentido do uso da biblioteca escolar como espaço de pesquisa e desenvolvimento de algumas competências como leitura e escrita.

Com relação ao primeiro aspecto observamos que a maioria dos professores possui um conceito muito limitado do espaço, prevalecendo na maioria dos discursos "um ambiente de pesquisa". De certo, o espaço é sim um ambiente de pesquisa, entretanto sua finalidade vai muito além. Compreendemos que a mesma é um espaço de aprendizagem que estimula a 
Lucas Veras de Andrade, Ana Caroline Viana Costa, Gisele Sousa Lobão Damasceno, Isaias Geovane Lima, 81 Iva de Carvalho da Silva, Patrícia Viana Cardoso, Renata Chaves de Oliveira, Theodolina Beserra Torres e

Willian Lamartins Amorim da Silva

leitura e o seu uso é capaz de formar cidadãos críticos. Nosso conceito entra em divergência com os discursos demonstrados pelos docentes, uma vez que entendemos que a biblioteca escolar sendo entendida como um lugar de pesquisa dá ao usuário uma posição apenas passiva de receptor, e na medida em que a percebemos como formadora de cidadãos críticos o sujeito passa a ser produtor de conhecimento e este estabelece uma relação de interação com a biblioteca. Essa concepção é defendida por Amaro (1998, p. 58) “a biblioteca interativa é um serviço de informação que busca estabelecer relações de interação entre o sujeito e a informação e a cultura para que o mesmo não seja só um receptor, mas também um produtor”.

Nesse sentido, com o estabelecimento de interação entre o sujeito e a biblioteca, este espaço deixa de ser apenas um ambiente disseminador de cultura e informação, para ser também um local de expressão.

Com relação à vivência destes frente o espaço em discussão, alguns não responderam o que denota uma não vivência e outros, cerca de $40 \%$ (quarenta por cento) colocaram o momento da graduação como o tempo de vivência com o mesmo.

No sentido do estímulo do uso da biblioteca pelos alunos, $70 \%$ (setenta por cento) afirmaram que sim, $20 \%$ (vinte por cento) confirmaram que frequentemente e $10 \%$ (dez por cento) disseram que raramente estimulam os alunos ao uso. Os primeiros estimulam com tarefas com pesquisas. Os que disseram frequentemente estimulam os alunos ressaltando a importância da leitura e por fim os que relataram raramente colocam o fator ausência do bibliotecário para o motivador para a falta de estimulo por parte deles.

Com base no exposto pelos discursos, procuramos ampliar a concepção dos professores a respeito do espaço em questão com um debate, na medida em que colocamos os discursos apresentados pelos mesmos em conjunto com o que apresentam alguns teóricos. Nesse sentido, nos utilizamos dos preceitos dos Parâmetros Curriculares Nacionais citados por Campello (2005) e Soares, Andrade e Sales (2011). Campello coloca o espaço da biblioteca escolar como um componente do contexto educacional com grande relevância para o desenvolvimento de competências para o século XXI e Soares, Andrade e Sales compreendem a biblioteca escolar como uma extensão da sala de aula e um elemento indispensável para a mediação e/ou transformação da informação em conhecimento.

Nossa explanação teve duração de duas horas e trinta minutos, um momento prazeroso onde os docentes puderam se posicionar e colocar algumas aflições com relação ao espaço da 
biblioteca escolar. Prazeroso porque houve diálogo e pudemos perceber que de fato o que ali estava sendo discutido estava sendo ouvido e o melhor com promessas de mudanças e transformações. As aflições segundo nossas observações, podem ser justificadas pela própria vivência ou não dos professores frente este espaço.

As experiências vivenciadas em bibliotecas universitárias são totalmente diferentes da biblioteca escolar, embora ambas tenham objetivos comuns. Embora alguns autores apenas as diferenciem com o grau acadêmico, afirmando que tenham o mesmo objetivo como Fonseca (2007), discordamos, pois a biblioteca escolar deve ter um olhar diferenciado, principalmente com relação ao lúdico, uma vez que o público geralmente são crianças.

Acreditamos que a vivência dos professores apenas com a biblioteca universitária, cujo objetivo é respaldar com infraestrutura, bibliografia e documentos os cursos da universidade, não permite que os mesmos enxerguem este espaço com esse olhar diferenciado e que desenvolvam atividades que aliem os espaços da sala de aula com a biblioteca, pois a vivência deste espaço no ambiente universitário muitas vezes se resume a leituras, empréstimos de livros e estudos individualizados e coletivos.

Nossa afirmação se fundamenta justamente pelos professores terem colocado a questão da dificuldade de pensarem em atividades que aliem as disciplinas ao espaço da biblioteca escolar e no "achismo" dos mesmos estarem incentivando os alunos na usabilidade da biblioteca com atividades de leitura e pesquisa. Desse modo, a próxima atividade explana como se trabalhar o conteúdo das disciplinas com atividades lúdicas no contexto da biblioteca.

\section{Atividade 3 - Aliando conteúdo das disciplinas ao contexto da biblioteca com atividades lúdicas}

Inicialmente colocamos em pauta o trabalho a partir de projetos pedagógicos. Neste sentido, apresentamos um relato de experiência de um dos componentes do grupo, desenvolvido pelo mesmo na sua prática docente na rede municipal de Teresina, que teve como objetivo ampliar as perspectivas de ensino-aprendizagem para além do trabalho em sala de aula, dando ênfase ao contexto da biblioteca escolar. 
Lucas Veras de Andrade, Ana Caroline Viana Costa, Gisele Sousa Lobão Damasceno, Isaias Geovane Lima, 83 Iva de Carvalho da Silva, Patrícia Viana Cardoso, Renata Chaves de Oliveira, Theodolina Beserra Torres e Willian Lamartins Amorim da Silva

Com este apresentamos várias possibilidades de trabalho. A partir do relato evidenciamos o uso do teatro tanto o encenado como o teatro de varas, leituras coletivas com discussões mediadas pelo professor, sempre aliando o ambiente da biblioteca a uma temática de sala de aula. Também foram apresentadas outras atividades como:

\section{Descobrindo história na biblioteca}

Os alunos instigados pelo professor ou pela pessoa responsável pela biblioteca são incitados a procurar livros antigos (qualquer gênero). Com o exemplar na mão, o alunado será instigado a pesquisar mais profundamente sobre os principais acontecimentos da época que data o livro. O professor de literatura pode também explorar autor, gênero e o próprio conteúdo da obra. É uma ótima forma de iniciar a explanação de um assunto no contexto da sala de aula. A atividade também pode proporcionar achados relevantes para a biblioteca, como a descoberta de um exemplar raríssimo (Olha que interessante e instigante!). Atividades desta natureza valorizam o acervo da biblioteca e exercitam bem como orientam a prática da pesquisa.

\section{Fazendo nossa biografia}

Hoje a maioria dos professores reclama que desconhecem seus alunos em função da correria da profissão. Esta é uma ótima atividade para esta aproximação. O professor de Língua Portuguesa solicita que os alunos busquem várias biografias de diversas personalidades no acervo da biblioteca. Após leitura na biblioteca e explanação das mesmas em sala, os alunos serão convidados a desenvolverem suas próprias autobiografias. Atividades deste tipo além de propiciarem aos alunos conhecimentos prévios para explanação do gênero biografia em sala de aula, desenvolvem a capacidade de concentração a partir da leitura e a competência da escrita na medida em que o aluno é convidado a escrever sobre sua história.

Atividades assim, também podem ser desenvolvidas mediante projeto pedagógico e sequência didática, nestes poderão ser ampliados todos os aspectos do gênero biografia, aumentando o leque de conhecimentos acerca deste gênero e suas vertentes pelos alunos e como culminância teríamos a produção de um livro com todas as biografias dos alunos. 
Nesta oportunidade, proferimos alguns encaminhamentos à pessoa responsável pela biblioteca. Ressaltamos a necessidade da mesma conhecer o acervo em todos os seus aspectos e que só a partir desta parceria professor/responsável pela biblioteca seria possível a concretização dos encaminhamentos que até então estávamos apresentando.

Encerramos esse diálogo com uma visita orientada com o grupo pedagógico, onde explicamos a classificação em cores e o sentido da mesma na biblioteca da escola. O intuito desta atividade foi de conscientizar os professores sobre o espaço da biblioteca escolar e que diversas são as atividades que podem ser desenvolvidas neste espaço em conjunto com a sala de aula.

\section{Outras atividades no contexto da biblioteca escolar que foram desenvolvidas e encaminhadas}

\section{Inventário e Criação da Política de Desenvolvimento de Coleções}

Observamos que a escola não possuía consciência quantitativa do acervo e critérios para a inserção e descarte de materiais no acervo da biblioteca. Nesse sentido, fizemos uma breve contagem do acervo que totalizou o montante como demonstrado no Quadro 1 e uma inacabada política de desenvolvimento de coleção. A Política de Desenvolvimento de Coleção é um documento institucional que apresenta a toda comunidade escolar, vários critérios para o desenvolvimento da coleção e tem por finalidade orientar a partir de parâmetros as responsabilidades para o desenvolvimento do acervo bibliográfico, dando ao profissional responsável pela biblioteca condições para planejar e avaliar as coleções, no sentido de assegurar o crescimento racional e equilibrado do acervo, de forma qualitativa e quantitativa.

A Política ainda serve como guia na consolidação de tomadas de decisões dos profissionais bibliotecários em relação ao desenvolvimento do acervo nos aspectos como: compra e descarte, doações e etc. Esta atividade incide diretamente sobre a quinta lei. A biblioteca é a depositária do conhecimento e neste sentido estar sempre em crescimento, pois a produção do conhecimento é contínua. E dessa forma, para que a biblioteca esteja preparada para acompanhar esse desenvolvimento é necessário que o profissional responsável por ela, em seu fazer profissional se utilize de mecanismos como a política de desenvolvimento de coleções para pensar nesse crescimento constante, ou seja, que não cessa. Campos ([2000?], 
Lucas Veras de Andrade, Ana Caroline Viana Costa, Gisele Sousa Lobão Damasceno, Isaias Geovane Lima, 85 Iva de Carvalho da Silva, Patrícia Viana Cardoso, Renata Chaves de Oliveira, Theodolina Beserra Torres e Willian Lamartins Amorim da Silva

não paginado) entende este processo de crescimento da biblioteca como um "Método Científico apresentado por Ranganathan e caracterizado pelo movimento sem fim em espiral".

\section{Considerações Finais}

A realidade da biblioteca na qual analisamos se mostra bem diferente da que podemos observar na literatura que geralmente demonstra o espaço da biblioteca cheia de fragilidades, como podemos observar em Balmant (2013, não paginado) que afirma que "em 72,5\% das escolas brasileiras não há biblioteca" e que ainda demonstra a precarização deste ambiente e em Silva (1999, p. 59), que diz que "boa parte das bibliotecas escolares está situada em espaço inadequado, em algum canto da escola, apertado, mal iluminado, enfim, desconfortável, fato que revela o baixo prestígio da biblioteca na escola".

Nosso diagnóstico constatou que a biblioteca possui condições ideais para seu funcionamento, entretanto, sofre com alguns obstáculos para o desenvolvimento de atividades em seu lócus, nestes colocamos em pauta o papel que é dado à presença física da pessoa que estar à frente da biblioteca. Uma biblioteca pode sim funcionar sem uma "pessoa" desde que seja implantada uma cultura para isso dentro do contexto escolar.

Nesse sentido, nossa intervenção foi executada com o objetivo de mudar tal situação. A biblioteca como encontrada apresentava-se como um depósito de livros e o sentido dado à pessoa responsável era a de guardião. Esta última afirmação se dá pelo motivo de a biblioteca só funcionar na sua presença.

O primeiro paradigma a ser quebrado é exatamente esse, é um paradigma tradicional e ultrapassado. O profissional da biblioteca escolar deve ser um articulador, proativo, inovador, comunicativo, criativo e tentar na medida do possível tornar o espaço da biblioteca o mais acolhedor e que o aluno se sinta bem em frequentá-lo.

Mesmo com a ausência de uma pessoa no espaço da biblioteca, cabe ao supervisor da escola e principalmente os professores fornecer condições para que este ambiente se mantenha vivo. Os professores porque muitas vezes cabe a ele, pela inexistência de uma cultura de leitura do brasileiro, introduzir os primeiros contatos dos livros com os estudantes.

O supervisor pela sua formação compete a ele desenvolver ações de orientação tanto aos professores quanto aos alunos bem como desenvolver atividades no contexto escolar que 
busquem a melhoria do ensino e aprendizagem. Uma vez detectados situações como esta relatada, compete a ele pensar em ações e estratégias que busquem reviver espaços inativos dentro do contexto escolar sejam através de projetos ou campanhas. $\mathrm{O}$ certo é não se manter neutro e no "achismo" de que nada posso fazer.

A intenção da nossa intervenção foi potencializar o máximo possível a usabilidade da biblioteca no contexto da escola mediante conscientização dos professores a respeito deste espaço bem como na usabilidade dos alunos a partir da autonomia que a classificação em cores dará a este ambiente pela praticidade de uso e organização.

Como última atividade, tivemos uma visita orientada ao espaço da biblioteca escolar com professores e alunos, lá orientamos os alunos quanto ao uso do acervo e demonstramos aos docentes o que encontramos inicialmente e o que estava sendo deixado bem como suplantamos qualquer dúvidas que ainda restavam e que não foram sanadas no momento da palestra.

Nossa intervenção finda no mesmo ponto em que se iniciou, com o olhar para o espaço da biblioteca escolar e com a esperança de que os trabalhos desenvolvidos na escola sejam dado continuidade e que toda equipe pedagógica da mesma tenha se conscientizado e não mais justifique, não trabalhar o espaço da biblioteca escolar pela ausência de uma pessoa no lócus em questão. Outro aspecto a ser ressaltado é que atividades simples podem ser inseridas no contexto de atividades no espaço da biblioteca a partir de conteúdos de disciplinas e o mais importante, de forma lúdica, empolgante e divertida, aspectos estes que chamam e muito a atenção dos alunos. Basta apenas criatividade por parte dos professores e o responsável da biblioteca.

Defendemos ainda a inserção do profissional bibliotecário neste ambiente porque ele é a figura ideal para gerir este espaço. O bibliotecário escolar pela natureza da sua formação é capaz de articular sua competência técnica as demandas escolares e as necessidades informacionais dos discentes, que faz deste um bibliotecário educador. O mesmo implica-se em buscar apoio e apoiar toda a comunidade escolar, principalmente os professores, pois a biblioteca sendo entendida como uma junção da sala de aula ele pode minimizar certas deficiências com relação a algumas habilidades demonstradas pelos alunos. Um exemplo são os programas e os projetos de incentivo a leitura que desenvolvem vários elementos relevantes para o ensino/aprendizagem: concentração, escrita e capacidade de leitura. 
Lucas Veras de Andrade, Ana Caroline Viana Costa, Gisele Sousa Lobão Damasceno, Isaias Geovane Lima, 87 Iva de Carvalho da Silva, Patrícia Viana Cardoso, Renata Chaves de Oliveira, Theodolina Beserra Torres e Willian Lamartins Amorim da Silva

\section{Referências}

AMARO, R. K. O. F. Biblioteca interativa: concepção e construção de um serviço de informação em ambiente escolar. 1998. 129f. Tese (Doutorado em Ciência da Informação e Documentação) - Escola de Comunicação e Artes, Universidade de São Paulo, 1998.

BRASIL. Lei no 12.244 de 24 de maio de 2010. Dispõe sobre a universalização das bibliotecas nas instituições de ensino do País. Disponível em:< http://www.planalto.gov.br/ccivil_03/_Ato2007-2010/2010/Lei/L12244.htm>. Acesso em: 14 mar. 2013.

BALMANT, O. Em 72,5\% das escolas não há biblioteca; lei prevê obrigatoriedade até 2020 . Estado de São Paulo On Line, São Paulo, 23 jan. 2013. Disponível em:< http://www.estadao.com.br/noticias/impresso,em-725-das-escolas-nao-ha-biblioteca-leipreve-obrigatoriedade-ate-2020-,987556,0.htm >. Acesso em: 27 abr. 2013.

CAMPELLO, B. A competência informacional na educação para o século XXI. In: A biblioteca escolar: tema para uma prática pedagógica. 2. ed. Belo Horizonte: Autêntica, 2005. p. 9-11.

CAMPOS, M. L. As cinco leis da biblioteconomia e o exercício profissional. [2000?]. Disponível em: http:<//www.conexaorio.com/biti/>. Acesso em: 17 fev. 2013.

FONSECA, E. N. Introdução a biblioteconomia. 2. ed. Brasília: Brinquet de Lemos, 2007.

FRAGOSO, G. M. Biblioteca na escola. Rev. ACB: Biblioteconomia em Santa Catarina, v. 7, n. 1, p. 124-131, 2002.

LAVILLE, C. A construção do saber: manual de metodologia da pesquisa em ciências humanas. Porto Alegre: Artes médicas, 1999.

LÜDKE, M. Pesquisa em educação: abordagens qualitativas. São Paulo: EPU, 1986.

PIMENTEL, G; BERNARDES, L; SANTANA, M. Biblioteca escolar. Brasília: Universidade de Brasília, 2007.

PINHEIRO, M. I. S. Classificação em cores: uma metodologia inovadora na organização das bibliotecas escolares do município de Rondonópolis-MT. Revista Digital de Biblioteconomia e Ciência da Informação, Campinas, v.7, n. 1, p. 163-179, jul./dez. 2009.

PINHEIRO, M. I. S; SACHETTI, V. F. P. Classificação em cores: uma alternativa para bibliotecas infantis. In: SEMINÁRIO BIBLIOTECA ESCOLAR: ESPAÇO DE AÇÃO PEDAGÓGICA, 3.,2004, Belo Horizonte. Anais... Belo Horizonte: UFMG, 2004. Disponível em: <http://www.eci.ufmg.br/gebe/downloads/319.pdf >. Acesso em: 16 fev. 2013.

SILVA, W. C. Miséria da biblioteca escolar. São Paulo: Cortez, 1999.

SOARES, J. F; ANDRADE, L.V.; SALES, W.N. O ambiente Escolar e a Atuação

Bibliotecária: um olhar de estagiários de Biblioteconomia no município de Teresina - PI. In: 
ENCONTRO REGIONAL DE ESTUDANTES DE BIBLIOTECONOMIA, DOCUMENTAÇÃO, CIÊNCIA DA INFORMAÇÃO E GESTÃO DA INFORMAÇÃO, 14., 2011, São Luís. Os novos campos da profissão da informação na contemporaneidade. São Luís: UFMA, 2011. Disponível em:

$<$ http://rabci.org/rabci/sites/default/files/O\%20AMBIENTE\%20ESCOLAR\%20E\%20A\%20 ATUA\%C3\%87\%C3\%830\%20BIBLIOTEC\%C3\%81RIA\%20um\%20olhar\%20de\%20estagi \%C3\%A1rios\%20de\%20Biblioteconomia\%20no\%20munic\%C3\%ADpio\%20de\%20Teresina \%20\%E2\%80\%93\%20PI.pdf.>. Acesso em: 16 fev. 2013

TARGINO, M. G. Ranganathan continua em cena. Ci. Inf.,Brasília, v. 39, n. 1, p. 122-124, abr. 2010. Disponível em: <http://www.scielo.br/scielo.php?script=sci_arttext\&pid=S0100$19652010000100008 \& \operatorname{lng}=$ en \&nrm=iso $>$. Acesso em: 16 fev.2013.

TRIVINÕS, A. N. S. Introdução à pesquisa em ciências sociais: a pesquisa qualitativa em educação: o positivismo, a fenomenologia e o marxismo. São Paulo: Atlas, 1987. 